\title{
A Crise da Venezuela: paz, segurança social e direitos individuais.
}

The Venezuela Crisis: peace, social security and individual rights.

Carolina Lazzaro Barbosa ${ }^{1}$

\section{Resumo}

O presente artigo analisa a atual crise que ocorre na República Bolivariana da Venezuela. São tecidos comentários sobre os vieses histórico, econômico e político que a problemática apresenta, de forma a expor a realidade multifacetada do país.

Nesse sentido, evidencia-se a necessidade de uma profunda incursão histórica no sentido de se elucidar as características do surgimento do país e de sua decorrente desenvoltura econômica, da sua dependência no commodity não renovável que é o petróleo e sua consequente atividade de exportação para os países desenvolvidos do mundo.

No mais, imperiosa é a demonstração dos surgimentos dos embates políticos do país, tal como suas interligações com o cenário internacional e com a economia mundial. E, dentro da crise, fazer menção ao problema humanitário e humano que tem se desenvolvido, tal como destacar a necessidade de se garantir os direitos individuais das pessoas humanas cidadão dessa nação.

Palavras-chave - Venezuela; Crise; Direitos Individuais; Paz; Segurança; Direitos Humanos; Política; Petróleo.

Key-words - Venezuela; Crisis; Individual Rights; Peace; Security; Human Rights; Politics; Petroleum.

\footnotetext{
${ }^{1}$ Bacharelanda da Faculdade de Direito da Pontíficia Universidade Católica de São Paulo - SP - Brasil (e-mail carolinalazzaro.97@gmail.com). Autora de artigos jurídicos.
} 


\section{Sumário}

Introdução. 1. Um país eminentemente produtor e exportador de petróleo. 2. Uma análise histórica. 3. Uma crise humanitária. 4. Análise da paz e segurança social frente aos direitos individuais. Conclusão. Referências.

\section{Introdução}

A crise da Venezuela tem deixado estarrecido o mundo, frente às grandes violações de direitos humanos por derradeiro da perpetuação de emNenhuma entrada de sumário foi encontrada.bates políticos e econômicos que, além de advirem de condições internas da República Bolivariana, também possuem traços definidores na seara internacional.

Enfatizam-se as violações dos direitos humanos que, infelizmente, estão ocorrendo no país, inclusive denunciadas pela Organização das Nações Unidas, como execuções extrajudiciais e tortura de opositores do governo de Nicolás Maduro.A Organização tem repreendido o uso de armas de fogo para dispensar multidões de manifestantes, tal como a prisão política de opositores. ${ }^{2}$

É nesse sentido que se faz ululante a necessidade de análise e conhecimento do ocorrido em terras do país que divide a fronteira com o Brasil, inclusive por conta do êxodo que tem causado a imigração de pessoas para os solos brasileiros.

No mais, a erosão de vida democrática é motivo de preocupações mundiais, haja vista que a crise política que assola o país é quiçá a mais gritante demonstração de ausência de democracia efetiva a parte ocidental do globo, não havendo qualquer respeito ao Estado Democrático de Direito.

Por conseguinte, necessária é a elucidação da história do país desde suas origens e primórdios, tal como de como sua economia desenvolveu-se e, concomitantemente, como sua política encorpou-se.

\footnotetext{
2 Disponível em: https://www.dw.com/pt-br/onu-denuncia-viola\%C3\%A7\%C3\%A3o-de-direitos-humanos-navenezuela/a-40301130 (acesso em 05/05/2019 às 22:32)
} 


\section{Um país eminentemente produtor e exportador de petróleo}

Ao se analisar a situação atual da República Bolivariana da Venezuela, primordial se faz a elucidação do passado histórico do país. Trata-se de um país sul-americano que possui enormes reservas de petróleo em seu território, o que a torna mundialmente reconhecida por ser a criadora da Organização dos Países Exportadores de Petróleo (OPEP) ${ }^{3}$. Os atuais - ano de 2019 - membros da OPEP são: Argélia, Angola, Equador, Irã, Iraque, Kuwait, Líbia, Nigéria, Catar, Arábia Saudita, Emirados Árabes Unidos e Venezuela.

Essa organização, datada dos anos 60, controla a exploração da commodity, importante gerador de energia não renovável do mundo atual, de modo que toda a política petrolífera resta por centralizar-se nas mãos dos países que dessa organização são membros. Por conseguinte, são desenvolvidas estratégias para que o preço do petróleo varie de acordo com a oferta produção de cada país, o que garante a alteração do preço do barril do petróleo em prol da maior lucratividade para esses países.

Em assim sendo, ululante se faz a importância econômica que a Venezuela possui na seara internacional. O petróleo ainda movimenta a economia mundial, em que pese estar fadado ao fim, mesmo que em um futuro distante e nebuloso. Com a alteração nos preços do barril de petróleo, a economia dos países é afetada, por conta de muitas transações internacionais serem cotadas com base no preço dos barris e por conta de o petróleo ser produto de comercializações entre nações.

No mais, por óbvio, as relações econômicas estabelecidas entre os países produtores/exportadores e os países importadores de petróleo geram, outrossim, o estabelecimento de relações diplomáticas. Por exemplo, os Estados Unidos da América do Norte possuem interesse no país por conta da dita reserva de petróleo, mas também por causa das demais reservas minerais, como de gás natural, ouro, urânio, bauxita, ferro, dentre outros minerais economicamente relevantes.

Assim, embora a política de ambos os países divirjam radicalmente, há uma interdependência econômica entre eles que requer que uma diplomacia minimamente funcional exista. Atual e historicamente, os EUA, como maior comprador do petróleo dessa potência petrolífera, sancionam a compra de petróleo - por exemplo, congelando os ativos da PDSVA (Petróleo da Venezuela, empresa estatal responsável pela exploração, produção, fabricação,

\footnotetext{
${ }^{3}$ Disponível em: https://mundoeducacao.bol.uol.com.br/geografia/opep.htm (acesso em 30/04/19 às 21:55)
} 
transporte e comercialização do petróleo ${ }^{4}$ ) e reduzindo as quantidades de importações ${ }^{5}$ - por conta da política venezuelana, o que acaba por afetar de forma inexorável e drástica a economia interna e, por derradeiro, a sociedade da Venezuela, conforme será analisado mais adiante.

Cabível é, pois, verificar o porquê que a Venezuela depende praticamente só da produção e exportação do petróleo para aquecer sua economia.

\section{Uma análise histórica}

A Venezuela é um país surgido da "Gran Colombia", no século XIX, cuja governança era centralizada por parte de militares e latifundiários. Quando da transição democrática, já no século XX, com o posterior início da exploração do petróleo, restaram ainda o traço histórico militarizado do país.

Atualmente, o país é grande exportador de petróleo do mundo, sendo que seu Produto Interno Bruto (PIB) pode ser representado, em grande parte, por esse setor de exportação de commodity. Anteriormente, a exportação agrícola era o motor da economia venezuelana. ${ }^{6}$

Com o investimento no setor petrolífero, em toda sua cadeia produtiva, de transporte e de comercialização criou-se a Petróleos Venezuela (PDVSA), de forma que a riqueza gerada se concentrava nas mãos de poucos e o mercado interno não era aquecido, características de uma economia subdesenvolvida. No mais, não mais se investiu em outras commodities ou no desenvolvimento agro-industrial do país, de forma que o petróleo passou a ser, cada vez mais, o cerne de toda a economia.

Com as Crises do Petróleo de 1973 e 1979, o aumento nos preços dos barris de petróleo foi benéfico para a economia do país, todavia, os investimentos feitos superaram as capacidades estatais de orçamento. Ademais, com o aumento de dívidas externas, o aumento dos preços, até um ponto benéfico, passou a afetar negativamente a economia com os altos juros internacionais. Por fim, com a estabilidade posterior dos preços do petróleo, a economia venezuelana quebrou, sendo necessário se firmar acordo com o Fundo Monetário Internacional, a inflação começou a subir e as condições de vida das pessoas lá residentes começaram a mudar.

\footnotetext{
${ }^{4}$ Disponível em: http://pdvdobrasil.com.br/pdvsa/ (acesso em 30/04/2019 às 21:43)

${ }^{5}$ Disponível em https://economia.uol.com.br/noticias/bbc/2019/02/26/crise-na-venezuela-quais-paises-compramo-petroleo-do-pais-sul-americano.htm (acesso em 30/04/2019 às 22:01)

${ }^{6}$ Disponível em: https://www.politize.com.br/crise-na-venezuela/ (acesso em 02/05/2019 às 17:55)
} 
O período de prosperidade econômica decorrente das Crises do Petróleo ocorreu sob a governança de Carlos Pérez. Porém, com a problemática econômica ocorrida depois, sua popularidade caiu e a população começou a se manifestar no evento conhecido como Caracazo.

Em pleno momento de instabilidade, um pouco a posteriori, ocorreu a eleição de Hugo Chávez, presidente que prometia a redistribuição de renda no país, luta contra a pobreza e consequente Revolução Bolivariana, em que foi estabelecida uma nova ordem constitucional. Aos poucos, poderes exorbitantes passaram a tecer parte da atuação do presidente, o que gerava insatisfação na população e preocupação no cenário internacional. A partir de então tentativas de golpes do poder começaram a tomar forma na Venezuela, mas Chavéz permaneceu presidente, ou, quando deposto, retomou o poder. Foi responsável por estatizar importantes setores da economia do país, principalmente o setor petrolífero, o que acabou por afastar os investimentos estrangeiros.

Com sua morte, Nicolás Maduro foi eleito em 2013, continuando o mandato de Chávez em meio a uma crise social e política, muito embora as políticas deste tenham surtido certo efeito na redução da pobreza. Convocou, então, uma nova constituinte, vista pelos países externos como um autogolpe, vez que se via como uma manobra política para se perpetuar no poder. Países da OPEP entraram, então, em desacordo com a Venezuela quando aos preços dos barris de petróleo, o que fez com que baixassem muito, pois houve uma recusa em diminuir a produção com o intuito de manter os preços. Concomitantemente, por discordância política e econômica, os EUA aumentaram a produção de xisto - alternativa ao petróleo -, de modo a suprir a anterior necessidade inexorável e insanável de importar da Venezuela.

A eleição de 2018 não foi reconhecida por parte da maioria dos países do mundo, em vista de sua aparente falta de legitimidade. Insta mencionar que a situação social continuava em um círculo vicioso em que a população estava desamparada e sem as mínimas condições de vivência digna, dependendo o país totalmente de importações dos produtos mais básicos ao consumo, vez que em momento algum foi feito investimento interno em outras áreas de produção. Juntamente com isso, insta salientar a inflação latente com a solução de injetar capital na economia, com a impressão de dinheiro, o que, por conseguinte, gerou exorbitante aumento de preços. Então, em busca de controlar artificialmente a inflação, foi estabelecida uma política cambial de obrigação aos comerciantes de baixarem seus preços, o que levou estabelecimentos à falência e causou figa de empresas do país.

Em janeiro do corrente ano de 2019, o até então líder da Assembleia Nacional autoproclamou-se presidente da Venezuela, exigindo novas eleições para o restabelecimento da 
paz e da liberdade democrática no país. Assim, a situação periclitante atual ultrapassa as fronteiras do território do país, de feitio que perseguições políticas têm se multiplicado, péssimas condições de vida têm se perpetuado e ajuda humanitária tem sido cada vez mais latentemente necessária. O cenário momentâneo é peculiar e preocupante, vez que o país possui dois presidentes internacionalmente reconhecidos, cada um por certo grupo de nações estrangeiras, de modo que as tensões têm crescido muito e causado grande pânico e consequente desenfreado êxodo da população.

Insta reiterar, por fim, que a dependência econômica exclusiva no petróleo agrava demasiadamente toda essa crise, vez que o país depende totalmente de importações de produtos básicos à população, por derradeiro do fato de que os investimentos em indústrias ou na agricultura foram quase nulos na maior parte de sua história de país explorador de petróleo.

\section{Uma crise humanitária}

O efeito da globalização no que tange à exclusão de países tidos como de "terceiro mundo" pode ser um fator apontado como gerador de problemáticas como o que tem tomado forma na Venezuela.

Caracteristicamente, países com denominados em desenvolvimento, responsáveis mundialmente pela produção e exportação de commodities, não investiram em real desenvolvimento interno nos seus mercados, de feitio que não acompanharam as necessidades mundiais de mudanças econômicas.

Nesse sentido, divergências políticas que buscam mudar o futuro da República Bolivariana da Venezuela baseiam-se, justamente, no colapso econômico decorrente da falta de investimentos no mercado interno e na própria população. Posicionamentos políticos muito opostos não se conciliam de modo algum, de forma que a situação decadente e degradante do país apenas se aprofunda.

Quanto à atuação internacional, deve-se atentar para o fato de que a crise humanitária que se estende por anos no país não pode ser um pretexto para a instauração de uma "guerra justa”, contra quaisquer das partes, ou quaisquer dos vieses político-econômicos.

Ideais seriam intervenções diplomáticas com ênfase em uma neutralidade positiva por parte dos países interventores, em prol da soberania do Estado Venezuelano e, ao mesmo tempo, em paládio dos direitos individuais dos indivíduos que no território habitam ou que deve estão emigrando. 


\section{Análise da paz e segurança social frente aos direitos individuais}

Conforme o analisado anteriormente, a Venezuela tem sido, há anos, palco de instabilidades e conflitos internos e externos. Nesse sentido, a população que lá reside, é afetada irrefutavelmente, de modo que seus direitos humanos básicos são negados cada vez mais, como o direito a uma vivência digna, direito a uma alimentação, direito à moradia, direito à livre expressão política, entre outros.

Assim, na análise do surgimento e desenvolvimento dos direitos individuais, imprescindível se faz sua análise histórica, normativa e sistêmica. Além dos elementos históricos, os filosóficos e os políticos também devem ser aclarados para uma plena compreensão dos direitos e de suas aplicações na situação elencada em tela.

Historicamente, o primeiro momento em que os direitos individuais têm seu aparecimento é no Antigo Testamento Bíblico, vez que seres humanos passaram a ser tidos como frutos iguais de Deus, destacando-se, pois, a igualdade mínima entre as pessoas.

Com o protestantismo e, a posteriori, com o início do capitalismo e com as Revoluções Burguesas, individualizou-se a pessoa humana, com destaque ao protestantismo do huguenotes.

O filósofo John Locke (1632-1704), fundador do liberalismo-político, em sua obra "Segundo Tratado sobre o Governo Civil"?, acredita que a sociedade é um acordo entre indivíduos que cedem suas liberdades para terem garantidos os seus direitos naturais. Nesse sentido, evidencia-se o pensamento segundo o qual os direitos individuais são a base de todo o Poder Estatal, de modo que cabe a este, em quaisquer ocasiões, salvaguardar essa proteção, sem ser cabível a violação do dever de seu paládio, mesmo que com fundamento na necessidade de garantia da paz e de seguridade social.

Nessa esteira, no cenário venezuelano, a aplicação dessa visão Lockeana deve prevalecer, para que os seres humanos que lá habitam, ou que de lá estão fugindo, tenham proteção internacional, por meios diplomáticos e de uso de poderes exortativos da Organização das Nações Unidas.

${ }^{7}$ LOCKE, John. Dois Tratados sobre o Governo. São Paulo: Martins Fontes, 2001. 
Essa proteção pode ser minimamente garantida à medida que cada movimento político seja muito bem pensado, sem abrir brechas para usos excessivos de força frente aos manifestantes políticos.

Sob essa égide, pode-se dizer, ademais, que, no enredo atual da Venezuela, essa visão Lockeana é perfeitamente aplicável no território do país, tal como no consequente cenário do refúgio, uma vez que, além de se combater a violação de direitos humanos decorrentes das faltas de condição de vivência e das perseguições políticas, as nações fronteiriças do país devem buscar ajudar a efetivar a guarida dos direitos individuais dos seres humanos migrantes como anteriores à necessidade de seguridade social também.

Todavia, o que acaba sendo aplicado nessa seara é uma visão Hobbesiana do binômio paz/seguridade social e direitos individuais. Thomas Hobbes (1588-1769), filósofo iluminista, em sua obra "Leviatã", em contrário senso, acredita que os direitos individuais devem ser garantidos apenas em épocas pacíficas. Frente a tempos de instabilidade política e social, a paz e a segurança social devem ser enfatizadas em detrimento dos direitos individuais. Isso ocorre pois a força tem sido usada como arma política, de forma que os seres humanos que possuem ou possuíam as terras venezuelanas como lar, sequer têm condições de comprar alimentos básicos no supermercado, dado o desabastecimento. E, aqueles que se deslocam do país para territórios vizinhos também ficam na miséria, dependentes de esmolas e da boa vontade de institutos de acolhimento de organizações não governamentais.

\section{Conclusão}

Portanto, conclui-se que a crise que se desenrola na República Bolivariana da Venezuela possui raízes antigas, sendo inexoravelmente necessárias incursões históricas para demonstrar o porquê do terrível cenário atual.

Como país explorador de petróleo, a Venezuela busca centralizar o poder da produção e conseqüentes preços da commodity, gerando conflitos como os menbros da OPEP.

E, a eleição de Hugo Chávez, seguida da Revolução Bolivariana, gerou a criação de poderes autoritários e exorbitantes, seguida de insatisfação da população e preocupação no

8 HOBBES, Thomas. Leviatã ou a Matéria, Forma e Poder de um Estado Eclesiástico e Civil. Tradução Rosina D’Angina, consultor jurídico Thélio de Magalhães. - São Paulo: Ícone, 2008. 
cenário internacional, principalmente com a estatização do setor petrolífero, tão importante para a economia do país e para atrair investimentos estrangeiros - que passaram, pois, a se afastar.

Nicolás Maduro perpetuou o governo de Chávez com a política do autogolpe, manobra política para se perpetuar no poder. Com a diminuição dos preços dos barris de petróleo e a queda nas compras por parte dos Estados Unidos, o país afundou-se na crise em que se encontra até hoje.

Atualmente, o âmbito internacional pode agir em vias diplomáticas, com ênfase em uma neutralidade positiva, em busca de resguardar os direitos individuais das pessoas que sofrem com os conflitos.

Assim, na visão atual da Venezuela, deve ser aplicada a visão de John Locke no que tange aos direitos individuais e a necessidade de garantia da paz e da segurança social. Isso porque a garantia destas últimas não pode servir de pretexto para que os direitos humanos da população sejam violados. O Estado Venezuelano, enquanto sujeito de Direito Internacional Público, deve resguardar seu povo, elemento constitutivo de seu próprio Poder Político.

E, além do mais, é papel da comunidade internacional agir em prol de todos os sujeitos internacionais, inclusive do ser humano, já considerado sujeito do Direito Internacional Público.

O ser humano é, indubitavelmente, sujeito internacional no momento contemporâneo, pois possui cidadania universal protegida pelo sistema internacional de proteção da pessoa humana. ${ }^{9}$

Na crise venezuelana, podem os indivíduos fazer reclamações à cortes internacionais em busca de resoluções de questões que os afetaram, como, por exemplo, junto à Comissão Europeia dos Direitos Humanos.

\footnotetext{
${ }^{9}$ HUSEK, CARLOS ROBERTO. Curso de Direito Internacional Público. 14. Ed. - São Paulo: LTr, 2017 , p.70.
} 


\section{Referências}

https://www.dw.com/pt-br/onu-denuncia-viola\%C3\%A7\%C3\%A3o-de-direitos-humanos-navenezuela/a-40301130 (acesso em 05/05/2019 às 22:32)

https://mundoeducacao.bol.uol.com.br/geografia/opep.htm (acesso em 30/04/19 às 21:55)

http://pdvdobrasil.com.br/pdvsa/ (acesso em 30/04/2019 às 21:43)

https://economia.uol.com.br/noticias/bbc/2019/02/26/crise-na-venezuela-quais-paises-

compram-o-petroleo-do-pais-sul-americano.htm (acesso em 30/04/2019 às 22:01)

https://www.politize.com.br/crise-na-venezuela/ (acesso em 02/05/2019 às 17:55)

LOCKE, John. Dois Tratados sobre o Governo. São Paulo: Martins Fontes, 2001.

HOBBES, Thomas. Leviatã ou a Matéria, Forma e Poder de um Estado Eclesiástico e Civil. Tradução Rosina D’Angina, consultor jurídico Thélio de Magalhães. - São Paulo: Ícone, 2008.

HUSEK, CARLOS ROBERTO. Curso de Direito Internacional Público. 14. Ed. - São Paulo: LTr, 2017, p.70. 